\title{
SOLAR ANALYSIS USING BUILDING INFORMATION MODELLING WITH THE GLASS BOX METHOD IN JAKARTA
}

\author{
Riva Tomasowa \\ Department of Architecture, Faculty of Engineering, Binus University \\ Jalan K.H. Syahdan No. 9, Palmerah, Jakarta Barat 11480 \\ rivatomasowa@binus.ac.id
}

\begin{abstract}
The utilisation of Building Information Modelling (BIM) focuses more on the Schematic Design or Technical Design phase, while the Preliminary or the Conceptual design is pretty much skipped. This paper shows that a simple model could utilise BIM to gain rich information about solar radiation to give ideal orientation in Preliminary phase. On this case, a spot in Jakarta is analysed with Glass Box method to depict the ideal orientation that receive a minimum solar radiation in a year span.
\end{abstract}

Keywords: solar analysis, BIM, glass box

\begin{abstract}
ABSTRAK
Penggunaan Building Information Modelling (BIM) selalu menitikberatkan pada tahapan perancangan skematik, sedangkan pada tahapan perencanaan awal dan konseptual sangatlah rendah. Tulisan ini bertujuan untuk menunjukan bahwa dengan pemodelan sederhana, model dapat disimulasikan untuk mendapatkan informasi terhadap orientasi matahari sebelum masuk kedalam tahap konseptual. Pada contoh kasus, lokasi di Jakarta yang dianalisa dengan metode kotak kaca ini menunjukan orientasi ideal yang menerima radiasi matahari secara minimum sepanjang tahun.
\end{abstract}

Kata kunci: solar analysis, BIM, glass box 


\section{PENDAHULUAN}

Overall Thermal Transfer Value (OTTV) adalah sebuah ukuran untuk konsumsi energi pada pelingkup bangunan. Dalam prinsip dasar OTTV, ukuran dari perpindahan panas pada pelingkup bangunan bergantung pada kalor yang diterima pada permukaan bangunan berbanding dengan luas area penerimanya. Berikut adalah rumus perhitungan OTTV secara umum:

$$
\text { OTTV }=\frac{Q_{w c}+Q_{g c}+Q_{s o l}}{A}
$$

$\mathrm{Q}_{\mathrm{wc}}$ adalah konduksi melalui dinding

$\mathrm{Q}_{\mathrm{gc}}$ adalah konduksi melalui jendela kaca

$\mathrm{Q}_{\text {sol }}$ adalah nilai radiasi matahari melalui jendela kaca.

Pada rumusan tersebut terdapat nilai $\mathrm{Q}_{\text {sol }}$ yang merupakan satuan lama radiasi dalam suatu luasan permukaan $\left(\mathrm{Wh} / \mathrm{m}^{2}\right)$. Oleh karena itu, OTTV secara prinsipnya adalah berbanding lurus dengan radiasi matahari yang diterima oleh suatu permukaan. Semakin tinggi Qsol, maka akan semakin meningkat pula nilai OTTV-nya yang mencerminkan tingginya penyerapan panas ke dalam bangunan (Vijayalaxmi, 2010). Walau dalam penelitian lebih lanjut oleh Prayudi, Fenz, \& Tjoa (2013), orientasi bangunan memiliki pengaruh yang kecil terhadap peningkatan OTTV. Hanya saja, nilai tersebut akan menjadi signifikan apabila ditempatkan sebuah bukaan.

Penelitian ini bertujuan untuk menunjukan bahwa dengan pemodelan sederhana, model Building Information Modelling (BIM) dapat disimulasikan untuk mendapatkan informasi Annual Integrated Direct Radiation pada sebuah orientasi yang akan berpegaruh pada nilai OTTV. Simulasi ini dapat dilakukan sebelum masuk ke dalam tahap perancangan konseptual, sehingga arsitek dapat mengambil keputusan yang lebih baik pada penempatan bukaan-bukaan pada bangunan. Hal ini merupakan penekanan dari pembahasan Hui (1997), mengenai software komputer yang dapat secara mudah dan lentuk untuk digunakan oleh para perancang.

\section{METODE}

Metode eksperimental ini dilakukan dengan alat bantu ArchiCAD 18, menggunakan Solar Analysis dari EcoDesigner18. Dalam eksperimen ini, disimulasikan 4 bentuk kotak kaca dengan berbagai macam penampang polygonal dengan sisi-sisi yang equilateral. Dengan begitu perbandingan antar sisi dapat dilakukan secara berimbang. Model-model tersebut adalah kotak-kotak kaca dengan penampang: bujur sangkar, pentagon, heksagon dan oktagon.

\section{HASIL DAN PEMBAHASAN}

Penelusuran eksperimental ini dilakukan pada lokasi Bandar Udara Internasional SoekarnoHatta, $6.120^{\circ} \mathrm{S}, 106,65^{\circ} \mathrm{E}$, Jakarta, yang disesuaikan dengan lokasi dari sumber data cuaca. Beberapa bentukan kotak kaca ditempatkan pada posisi tersebut dengan tujuan mencari radiasi yang jatuh pada permukaan jendela kaca. Bukaan kaca tersebut adalah identik satu sama lainnya, sehingga dapat dibandingkan secara ekuivalen. Berikut adalah sampel dari bentuk-bentuk yang digunakan: 

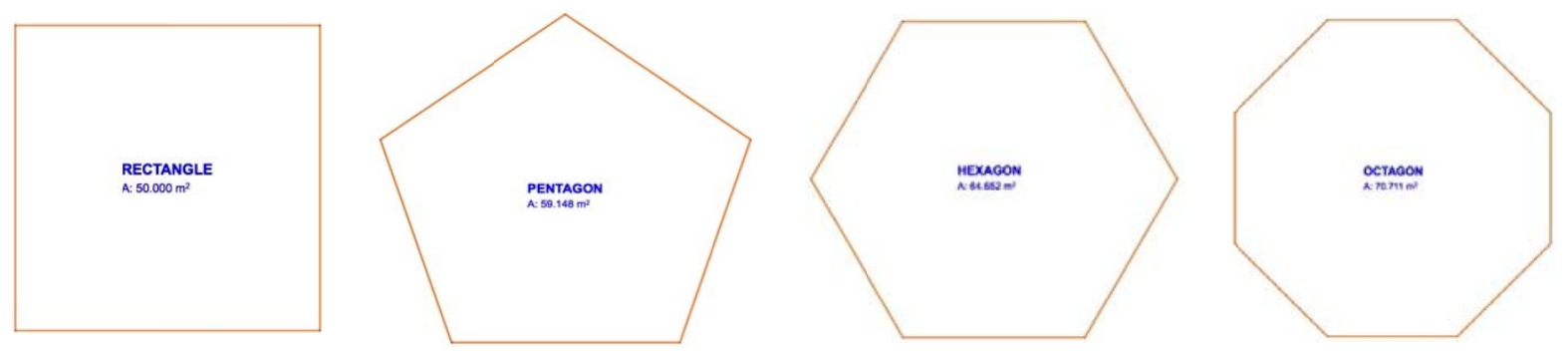

Gambar 1 Berbagai Penampang Polygon dari Pemodelan Kotak Kaca dengan BIM

Seluruh kotak kaca pada Gambar 1 berorientasi arah Utara sejati ke arah atas kotak kaca dijadikan sebagai pemodelan awal, karena bentuk sederhana ini memenuhi elemen-elemen standar untuk dilakukannya simulasi analisa matahari oleh EcoDesigner 18. Sebagai catatan, pemodelan Building Energy Model (BEM) memerlukan elemen-elemen minimum seperti: walls, slab, roof dan yang terpenting adalah zone. Melalui elemen-elemen tersebut perilaku ruang atau operation profile. Operation profile pada sample ini adalah Residential -- Rumah tinggal.

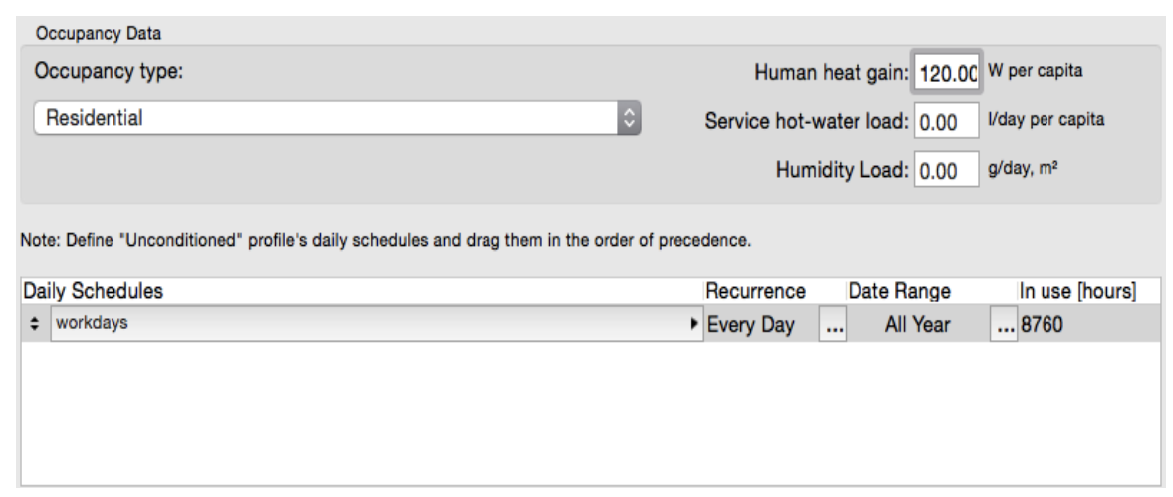

Gambar 2 Operation Profile Setting

Gambar 2 di atas, human heat gain adalah $120 \mathrm{~W}$ berdasarkan standar ASHRAE (ASHRAE, 2011) untuk duduk atau aktivitas ringan. Kemudian data yang dibutuhkan adalah beban penggunaan air panas dan humidity load, namun kedua data ini tidak diperlukan rinciannya dalam simulasi kotak kaca ini. Pada kotak kaca pertama yaitu Bujur sangkar, didapatkan perbandingan hasil dari 4 hadapan mata angin: Barat Laut, Timur Laut dan Selatan. Arah Timur Laut memiliki nilai radiasi tahunan tertinggi, sedangkan arah Selatan memiliki nilai terendah.

Tabel 1 Solar Analysis - Square

$\mathrm{N}$

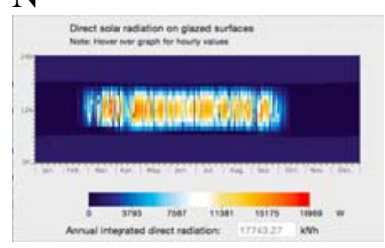

E

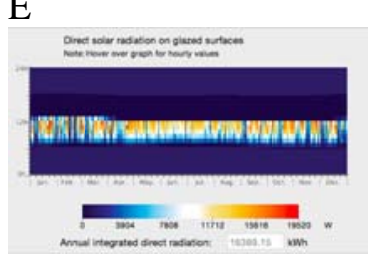

S

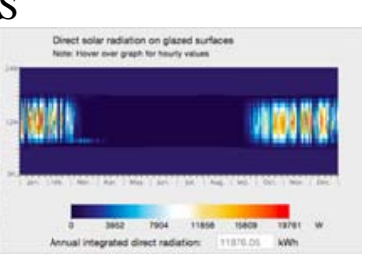

$\mathrm{W}$

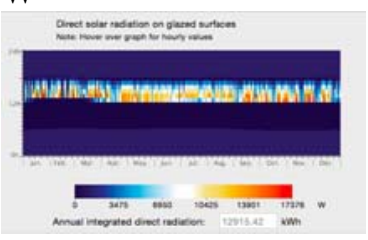




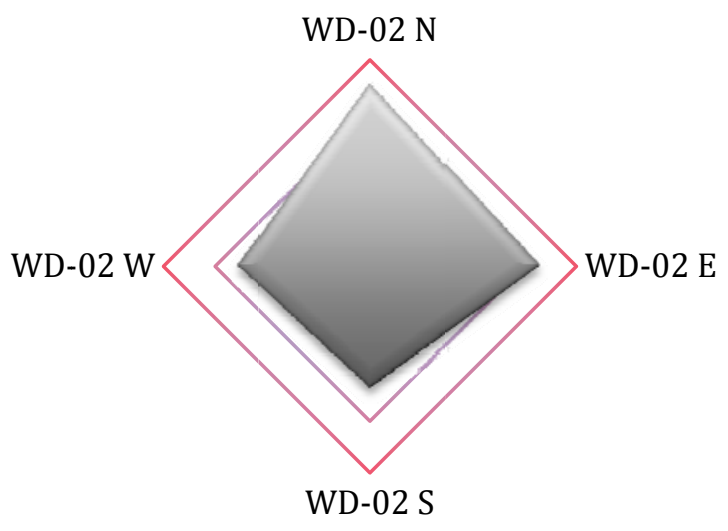

Gambar 3 Ratio Penerimaan Radiasi Tahunan pada Bentuk Bujursangkar

Dari Gambar 3 perbandingan di tersebut, dapat dilihat bahwa bagian Utara cenderung memiliki tingkat radiasi yang lebih tinggi. Dalam simulasi kotak kaca Bujur sangkar ini orientasi yang kurang bagus dimiliki arah Utara dan sebagian Timur. Kemudian simulasi dilanjutkan dengan menambah variabel arah jendela kaca. Dengan demikian bentuk penampang equivalent yang di dapat adalah Segi Lima (Pentagon). Dalam representasi Gambar 3 perbandingan di bawah ini (grafik terlihat dalam rotasi $180^{\circ}$ ), titik berat arah radiasi masih berada di arah Utara. Namun, dalam simulasi kali ini didapatkan arah Timur Laut memiliki tingkat radiasi tertinggi dan diikuti oleh arah orientasi Barat. Arah Selatan masih menduduki posisi penerimaan radiasi terendah.

Tabel 2 Solar Analysis - Pentagon

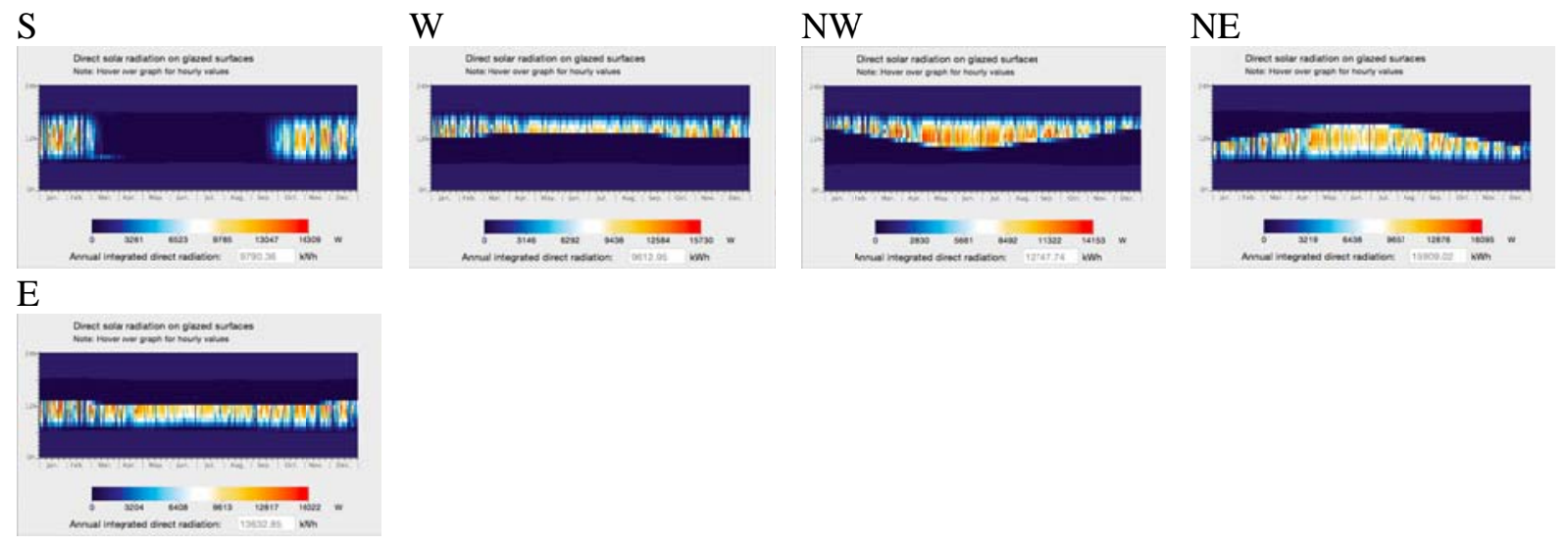




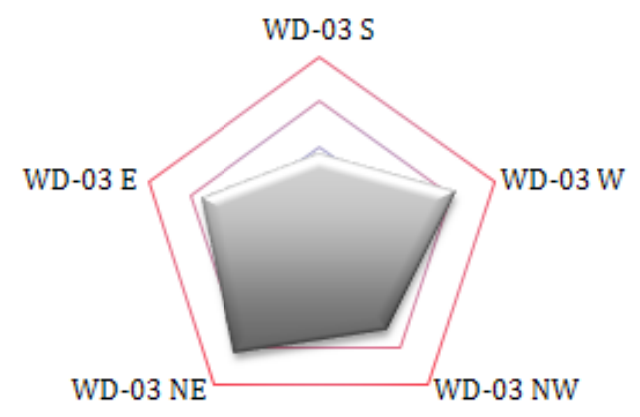

Gambar 4 Ratio Penerimaan Radiasi Tahunan pada Bentuk Segi Lima

Simulasi ketiga adalah kotak kaca dengan bentuk penampang Segi Enam atau Hexagon. Hasil simulasi ini, Gambar 4, menunjukan ada dua arah yang bertolak belakang memiliki nilai yang ekstrim. Arah tersebut adalah Barat Daya, yang memiliki tingkat radiasi yang signifikan tinggi, ketimbang arah orientasi lain. Di sisi lain, arah orientasi Tenggara pun memiliki nilai yang signifikan rendah. Sampai pada ketiga simulasi ini, kecenderungan arah Utara memiliki radiasi tertinggi dibanding Selatan masih relevan.

Tabel 3 Solar Analysis - Hexagon

$\mathrm{N}$

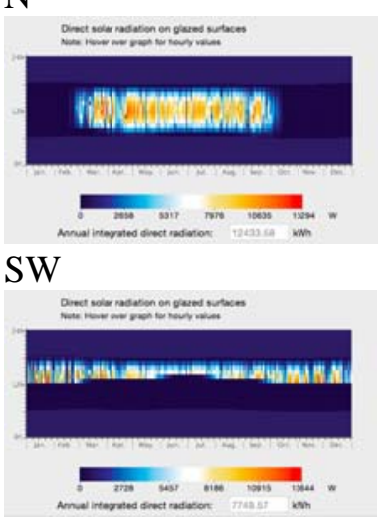

NE
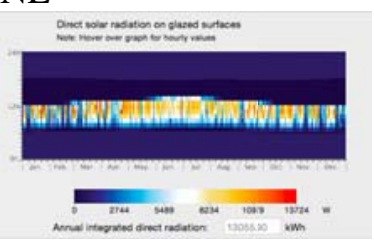

NW
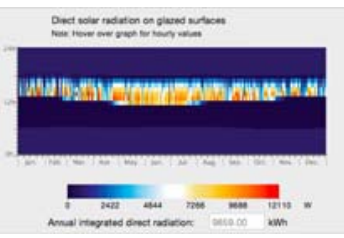

SE

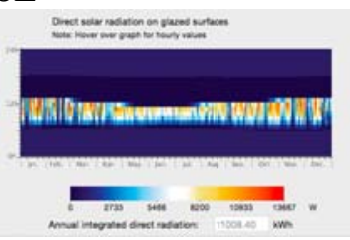

S

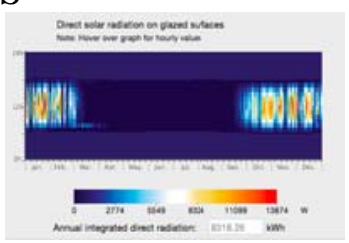

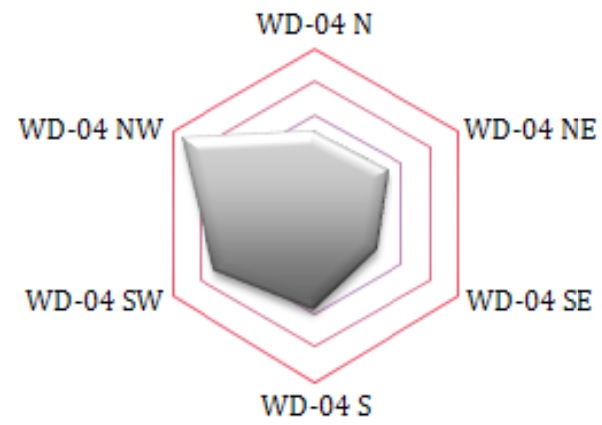

Gambar 5 Ratio Penerimaan Radiasi Tahunan pada Bentuk Segi Enam 
Bentuk penampang terakhir adalah Oktagon yang memiliki 8 arah aksial searah mata angin. Tabel 4 Solar Analysis - Octagon, memperlihatkan radiasi satu sisi dan sisi lawan arahnya. Perbandingan intensitas orientasi Utara terdeteksi lebih besar dari arah Selatan yang hanya hadir sekitar 5 bulan. Sedangkan Timur Laut berbanding Barat Daya menunjukkan intensitas pagi hari hingga siang hari sepanjang tahun merupakan waktu-waktu dominan dimana radiasi matahari memancar dengan kekuatan yang besar. Pada orientasi Tenggara dan Barat Laut, konsentrasi intensitas radiasi berkutat pada siang hari, sekitar pukul 09:00 WIB hingga 15:00 WIB.

Tabel 4 Solar Analysis - Octagon

$\mathrm{N}$

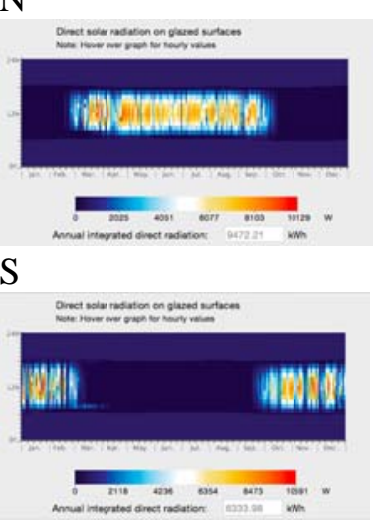

$\mathrm{NE}$

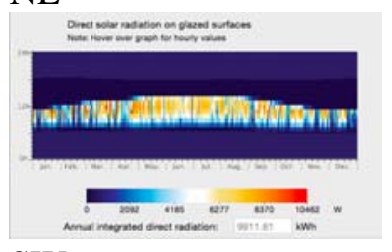

SW

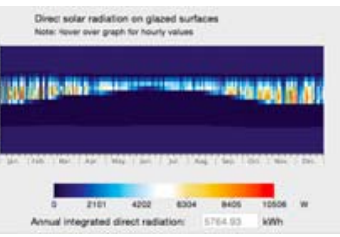

$\mathrm{E}$

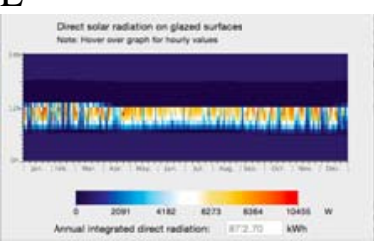

$\mathrm{W}$

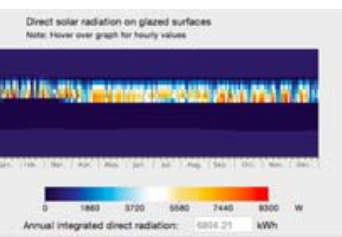

SE

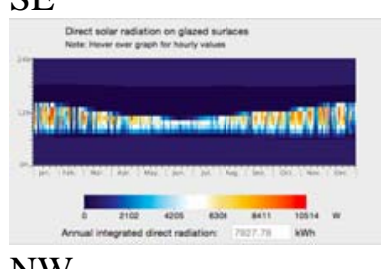

NW

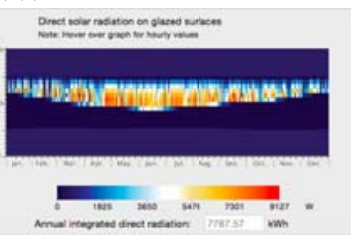

Hasil akumulasi yang terdata pada Gambar 5, kotak kaca segi delapan ini pun memiliki kondisi yang kontras antara arah Utara dan Selatan, dimana arah Utara masih cenderung mendapatkan radiasi yang tinggi berbanding dengan arah Selatan yang cenderung rendah. Jendela arah Timur Laut menerima radiasi terbesar sepanjang tahun, kemudian di posisi berikutnya adalah jendela arah Utara yang berbeda tipis. Di arah orientasi Barat Daya memiliki nilai terendah dan Selatan pada posisi berikutnya yang menerima radiasi dengan intensitas rendah. Kondisi ini menguatkan bahwa posisi Utara mendapatkan radiasi lebih dibanding arah Selatan.

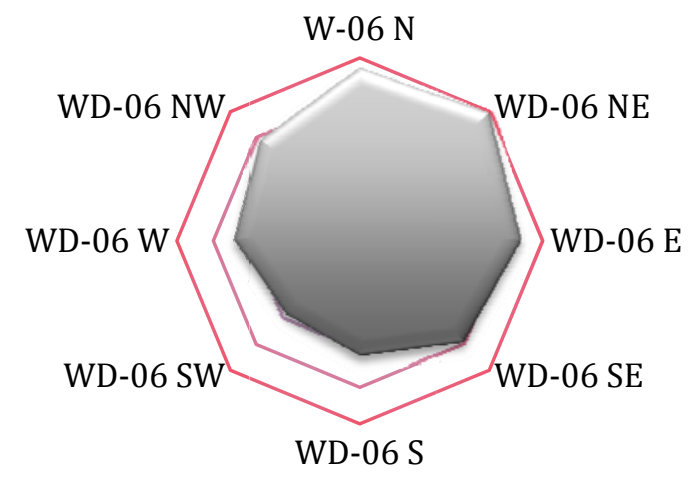

Gambar 6 Ratio Penerimaan Radiasi Tahunan pada Bentuk Segi Delapan

Dalam menganalisa radiasi matahari, menggunakan metode kotak kaca dalam aplikasi ArchiCAD 18 ini, banyaknya sisi-sisi ekuilateral merupakan variabel dari tingkat kejelasan orientasi. Dengan kata lain, semakin banyak sisi yang di buat akan memberikan gambaran orientasi yang 
semakin kritis atau jenuh. Bentuk kotak kaca dalam metode ini dapat dimodifikasi menurut orientasi yang ingin dibandingkan. Apabila bentuk arsitektur ideal muncul dari konteks tapak, maka pengaruh tersebut dapat memberikan batas-batas pada orientasi. Dengan begitu, ratio sisi-sisi akan lebih akurat. Analisa matahari ini selayaknya dilakukan pada tahap Preparation and Brief, mengacu pada RIBA Plan of Work 2013.

Keakuratan nilai radiasi pada simulasi ini memang belum bisa diandalkan sepenuhnya, mengingat banyak hal yang menjadi parameter. Baik parameter yang sudah ada di dalam software, maupun aspek-aspek yang belum ada atau dihiraukan. Namun selama parameter tersebut adalah konstan, maka perbandingannya pun akan membandingkan hal-hal yang menjadi variabel saja, yaitu arah orientasi. Eksperimen ini mencoba menunjukan perbandingan tersebut.

\section{SIMPULAN}

Dengan permodelan sederhana dan empat simulasi di atas, serta ratio perbandingan pada Gambar 7, dapat disimpulkan bahwa arah orientasi Utara memiliki kecenderungan menerima radiasi dalam jumlah lebih besar, ketimbang orientasi Selatan. Namun dalam membandingan arah Barat dan Timur masih belum dapat dilihat perbedaan yang signifikan dan konsisten. Simpangan sisi lainnya yaitu Timur Laut, mungkin dapat memberikan gambaran bahwa akumulasi di sisi Timur memang lebih besar dari arah Barat.

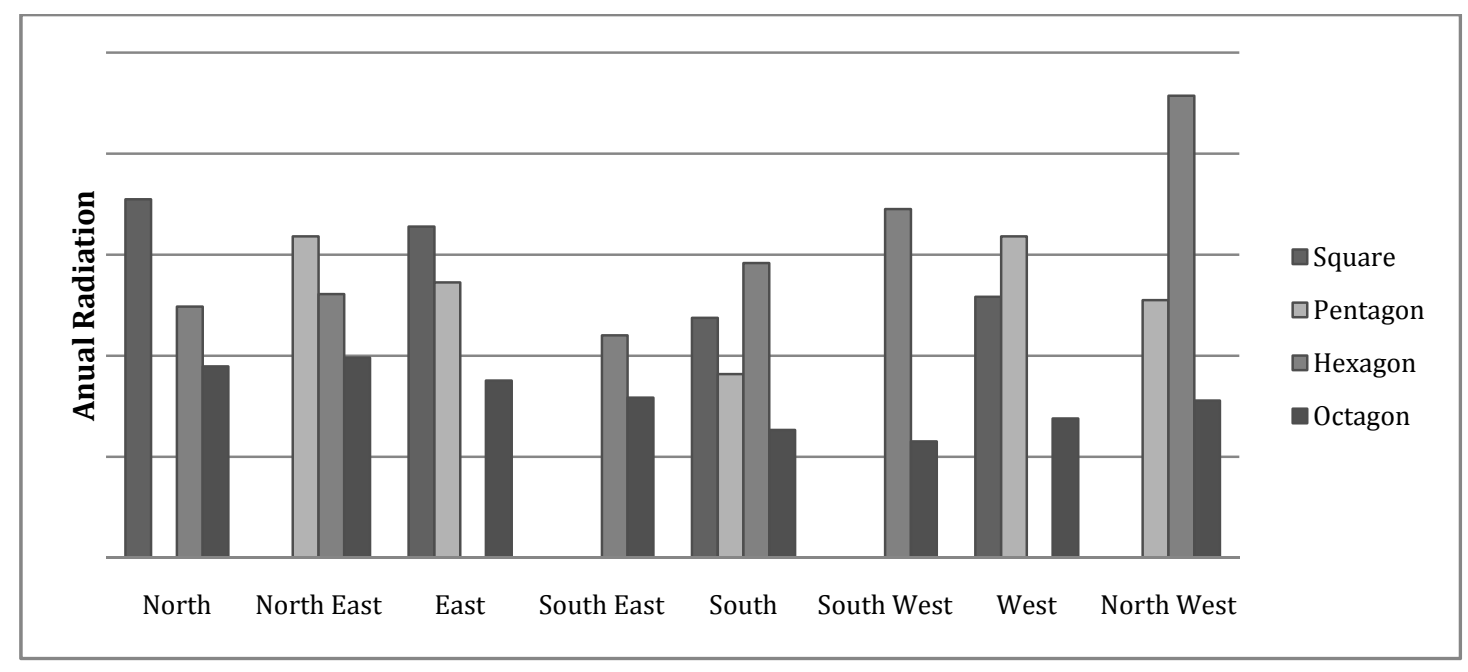

Gambar 7 Perbandingan Bentuk yang Disimulasikan Berdasarkan Data Radiasi

Dari gambaran besar arah orientasi terbaik untuk bukaan, jendela, di daerah Jakarta, terutama di seputar Bandar Udara Internasional Soekarno Hatta adalah orientasi arah Selatan dan Tenggara, karena dari dua arah orientasi tersebut menunjukan nilai penerimaan radiasi yang konsisten rendah pada keempat simulasi yang dilakukan. Metode pemodelan dan simulasi cepat ini juga menunjukan kapabilitas BIM dalam melakukan analisa pada tahap perancangan awal yang dapat memberikan gambaran kepada arsitek. Informasi yang diberikan dapat membantu arsitek dalam mengambil keputusan yang lebih baik. 


\section{DAFTAR PUSTAKA}

ASHRAE. (2011, May). ASHRAE Mechanical Pocket Guide. Retrieved February 2015 from BIM Wikispaces: http://bim.wikispaces.com/file/view/ASHRAE+Mechanical+Pocket+Guide.pdf

Hui, S. C. (1997). Overall Thermal Transfer Value (OTTV): How to Improve Its Control in Hong Kong. Proceeding of the One-day Symposium on Building, Energy and Environment. Kowloon, Hong Kong. 12-1 to 12-11.

Prayudi, I., Fenz, S., \& Tjoa, A. (2013). Study on Indonesian Overall Thermal Transfer Value (OTTV) Standard. International Journal of Thermal \& Environmental Engineering, 6 (2), 49-54.

Vijayalaxmi, J. (2010). Concept of Overall Thermal Transfer Value (OTTV) in Design of Building Envelope to Achieve Energy Efficiency. International Journal of Thermal \& Environmental Engineering, 1 (2), 75-80. 